\title{
Novel Risk Based Assessment of Pressure Vessels Integrity
}

\author{
Tamara GOLUBOVIĆ, Aleksandar SEDMAK, Vesna SPASOJEVIĆ BRKIĆ, Snežana KIRIN, Ivan RAKONJAC
}

\begin{abstract}
New methodology for risk based approach to integrity assessment of pressure vessels has been introduced. Namely, the risk matrix has been defined with consequence taken as usual, whereas probability has been separated into two, emphasizing effects of human factor and material defects. Toward this end, the failure assessment diagram (FAD) has been used here as a simple engineering tool to estimate probability of the failure due to material defects. Probability of failure due to human factor has been estimated according to the survey performed (with operators and managers) in the firm where pressure vessel is located and operated. With consequence estimated according to the simple standard procedure or by using more complex procedures (API 581, RIMAP), the novel risk based structural assessment has been completed. As an example, cylindrical storage tanks for compressed air are analysed.
\end{abstract}

Keywords: pressure vessel; risk based approach; structural integrity assessment; survey

\section{INTRODUCTION}

Pressure vessels represent critical welded constructions from the point of view of eventual failure and possible catastrophic consequences. Even though probability of failure is very low, at least based on previous experience, risk is still not negligible, having in mind consequences, as explained in [1-2]. Risk based approach is often explained by the risk matrix, Fig. 1, using the simple definition of risk (product of probability and consequence). Even in that case, there are different options, some of them recently introduced [3-8], which turned out to be efficient and useful engineering tool, especially for managers when they have to make difficult decisions. Anyhow, simple methods do not provide precise solutions generally speaking. Contrary to that, more complicated ones (e.g. API procedure, [9, 10], or its European competitor, RIMAP, [11], both based on empirical rules), provide more precise solutions, but usually require too much effort and time.

\begin{tabular}{|c|c|c|c|c|c|c|}
\hline & & \multicolumn{5}{|c|}{ Consequence category } \\
\hline \multirow{6}{*}{ 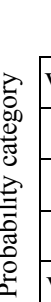 } & & $\mathrm{VL}$ & $\mathrm{L}$ & $\mathrm{IM}$ & $\mathrm{H}$ & $\mathrm{VH}$ \\
\hline & $\mathrm{VH}$ & Medium & High & High & Very high & Very high \\
\hline & $\mathrm{H}$ & Low & Medium & High & High & Very High \\
\hline & $\mathrm{M}$ & Low & Medium & Medium & High & High \\
\hline & $\mathrm{L}$ & Very low & Low & Medium & Medium & High \\
\hline & VL & Verylow & Very low & Low & Medium & Medium \\
\hline
\end{tabular}

Therefore, here we present yet another relatively simple method, based on new definition of risk matrix, i.e. new method to assess probability, interpreted here as twofold quantity. Namely, two most important factors for eventual failure of pressure vessels, human factor and material defects, are treated separately, "producing" two types of probability and thus new approach to risk assessment. Toward this end, the Failure Assessment Diagram (FAD), Fig. 2, has been used here as simple engineering tool to estimate probability of the failure due to material defects, taken as the function of the position of the operating point. Namely, probability of failure due to crack-like defect has been recently defined as the ratio between the distance of the operating point from the zero point, and the appropriate distance between the point on the limiting curve and zero point, [4-6]. This can be used regardless of defect existence, since one can also assume crack existence, just for the sake of a conservative approach, in the same way as it is sometimes done in a design phase.

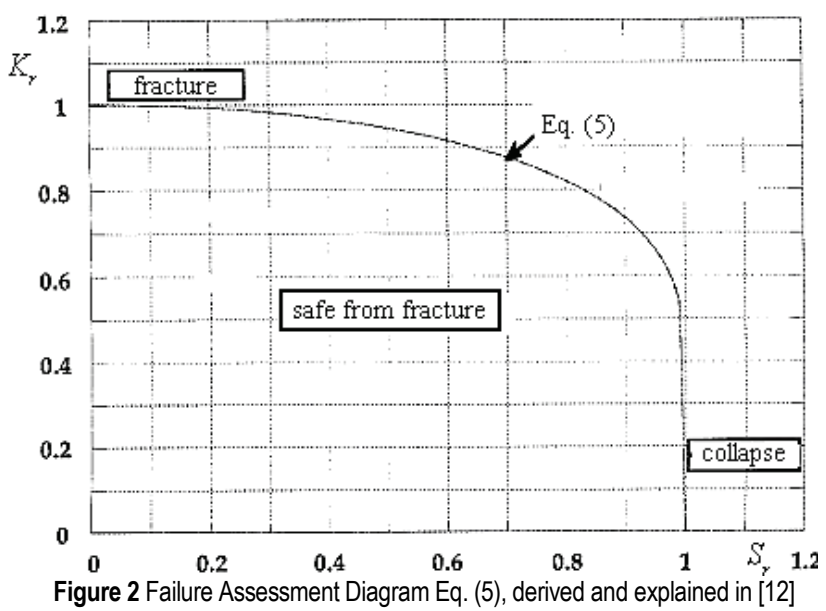

Probability of failure due to human factor can be estimated according to the survey performed in the firm where pressure vessel is located. Namely, it is also reasonable to assume that the probability of failure of pressure vessel is inverse proportion of human factor, if one takes for granted that operational staff have done everything to prevent failure. Actually in that case one can say the probability is 0 , whereas in the opposite case, e.g. complete negligence of staff, probability is equal to 1 . To assess any value in between, one can use answers given in a survey, based on questionnaire, as explained later.

\section{RISK BASED APPROACH - NEW METHODOLOGY}

In the risk matrix shown in Fig. 1, consequences and probabilities are categorized very low (VL), low (L), medium $(\mathrm{M})$, high $(\mathrm{H})$ to very high $(\mathrm{VH})$. The risk is then taken as the product of these two, leading to differently marked fields, sometimes presented in different colours, green (VL \& L), orange $(\mathrm{M})$, brown $(\mathrm{H})$ and red $(\mathrm{VH})$. This is obviously an oversimplified and somewhat arbitrary approach, but popular in modern management practice, especially when first round of decision making process is 
going on. Anyhow, since pressure vessels failures often have very heavy consequences, including fatalities, ecology disasters and doom day scenario for a firm, this problem certainly requires more complex analysis and more precise quantification of consequence and probability.

Table 1 List of questions used in this research

\begin{tabular}{|c|c|}
\hline No & Question \\
\hline 1 & I mostly report only major problem \\
\hline 2 & $\begin{array}{l}\text { My company does not have a precisely defined system according to } \\
\text { which we are informed about lessons learned during failures and } \\
\text { accidents. }\end{array}$ \\
\hline 3 & $\begin{array}{l}\text { When taking over my shift, there is an exact procedure to which I } \\
\text { must comply, related to obtaining of all the necessary information } \\
\text { from the previous shift. }\end{array}$ \\
\hline 4 & $\begin{array}{l}\text { When I am working under pressure, (breaking through deadlines } \\
\text { and suffering financial losses), managers who communicate with us } \\
\text { are fully focused on finishing our tasks as quickly as possible and do } \\
\text { not warn us about following safety procedures. }\end{array}$ \\
\hline 5 & $\begin{array}{l}\text { In my company, we often discuss process safety and managers ask } \\
\text { for our opinions on the matter. }\end{array}$ \\
\hline 6 & $\begin{array}{l}\text { rds for each individual material and } \\
\mathrm{ng} \text { with in the company. }\end{array}$ \\
\hline 7 & afety is rar \\
\hline 8 & $\begin{array}{l}\text { When missing deadlines and facing financial losses, our following } \\
\text { of processes and process safety procedures is affected in the } \\
\text { following way: } \\
\text { 1. All procedures are entirely and strictly followed regardless of the } \\
\text { circumstances } \\
\text { 2. Most procedures are followed regardless of the delay, although } \\
\text { some smaller rules may be overlooked } \\
\text { 3. Assessments are made about what can be skipped and what can } \\
\text { be finished in a safe way } \\
\text { 4. The priority is to get the job done, while it is assumed that we will } \\
\text { do everything we can to follow the main procedures } \\
\text { 5. No attention is paid to the procedures if the deadlines are } \\
\text { significantly missed, the only thing that is important is to finish as } \\
\text { soon as possible. }\end{array}$ \\
\hline 9 & out working hours and overtime are not always \\
\hline 10 & ned about hazards \\
\hline 11 & $\begin{array}{l}\text { During non-routine operations or repairs, following activities take } \\
\text { place in our company: } \\
\text { 1. One of the superiors supervises the work from beginning to end. } \\
\text { 2. One of the superiors is in charge of monitoring the operation from } \\
\text { beginning to the end only if operation is regarded as highly risky, } \\
\text { and if not, we just inform superiors how the repair is advancing. } \\
\text { 3. All non-routine repairs are monitored by the superiors from } \\
\text { beginning to the end, but they do not have to be necessarily } \\
\text { present and check them personally. } \\
\text { 4. We performn on-routine operations on our own, but must inform } \\
\text { the superiors of any major steps that we undertake. } \\
\text { 5. We perform non-routine operations on our own and are } \\
\text { responsible for finishing them properly }\end{array}$ \\
\hline 12 & $\begin{array}{l}\text { ce are always } \\
\text { is. }\end{array}$ \\
\hline 13 & $\begin{array}{l}\text { jo job are } \\
\text { in the }\end{array}$ \\
\hline 14 & $\mathrm{ks}$ for \\
\hline 15 & $\begin{array}{l}\text { We undergo regular trainings for responding in the case of } \\
\text { emergency (wherein we learn specific hazards related to our } \\
\text { workplaces, how to identify them, how to act when we identify } \\
\text { them and what kind of emergency response plan should be used in } \\
\text { case of an accident). }\end{array}$ \\
\hline 16 & nt drills durinosubish the \\
\hline 17 & $\begin{array}{l}\text { Whenever a process changes, or a new one is introduced, all } \\
\text { employees undergo training about the hazards related to that } \\
\text { process. }\end{array}$ \\
\hline 18 & apany. \\
\hline
\end{tabular}

Regarding consequence, instead of descriptive and somewhat arbitrary estimation based on several parameters (health, safety, environment, business, security), one can use technical data for a given pressure vessel (e.g. p, V, T, operating medium). In this way standard classification can be provided, from 0 to 4 , naturally leading to five levels of consequence, defined in the risk matrix.

Regarding probability, as already explained, it is separated into two major affecting factors, material defects and human factor. In the case of crack-like defects there is already new, interesting concept, based on fracture mechanics approach, applied recently for large spherical storage tank [6] and cylindrical pressure vessel [8], using the FAD to assess structural integrity of a cracked component. The basic concept of FAD is to evaluate ratios between the stress intensity factor and fracture toughness (Y coordinate), which can be interpreted as the probability of brittle fracture, and between the local stress and its critical value ( $\mathrm{X}$ coordinate), which can be interpreted as the probability of plastic collapse, Fig. 2. The point defined by these two coordinates is either in the safe or in the unsafe region, which are separated by the limit curve. Probability of failure can be estimated in the same way, as the ratio of the distance from the point to zero point and the distance from the corresponding point at the limit curve and zero point.

Finally, as already explained, probability of failure due to human factor can be estimated according to the survey, based on questionnaire given in Tab. 1. Toward this end, especially designed questionnaire has been used to perform a survey in a number of firms running pressure vessels in everyday practice. Selected questions are presented in Tab. 1, whereas the complete questionnaire is presented and analysed in [13].

\section{CASE STUDY - CYLINDRICAL PRESSURE VESSEL}

This pressure vessel has been used in Hydro Power Plant Bajina Basta, EPS, for many years before the regular NDT (radiography) has revealed non-acceptable defects according to standards, as shown in Fig. 3, and explained in more details in [14].

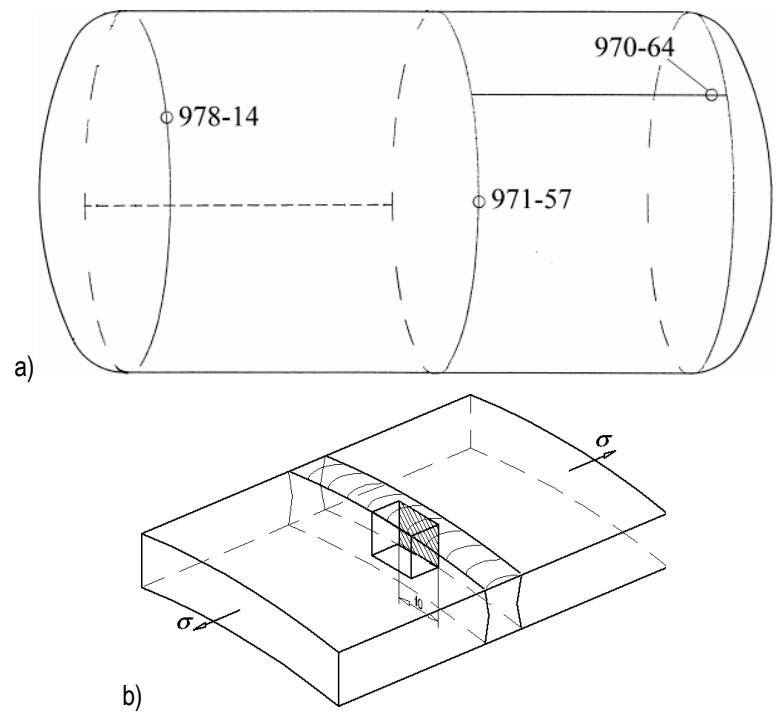

Figure 3 a) pressure vessel with defects; b) cross section with defect 971-57 
Consequence in this case is simple to evaluate because of the fact that eventual failure would cause catastrophic consequences, or in the best case, chaos, [15], but most probably fatalities as well. Therefore, it could be only $\mathrm{VH}$ consequence, even though contained medium is not harmful, i.e. toxic.

To evaluate probability due to material defects, one of three most dangerous has been picked up, namely defect 971-57, which has been identified as the lack of fusion, and is represented here as a through crack, Fig. $3 \mathrm{~b}$ to enable conservative approach and simple 2D analysis, at the same time, using the following data:

- Geometry: thickness $t=50 \mathrm{~mm}$, diameter $D=2075$ $\mathrm{mm}$;

- Material: high strength low alloyed (HSLA) steel: $R_{\text {eh }}$ $=500 \mathrm{MPa}, R_{\mathrm{M}}=650 \mathrm{MPa} ; K_{\mathrm{Ic}}=1580 \mathrm{MPa} \sqrt{\mathrm{mm}}$

- Crack geometry: length $10 \mathrm{~mm}$, circumferential weld -lack of fusion;

- Loading: maximum pressure $p=8.1 \mathrm{MPa}$, residual stress $\sigma_{\mathrm{R}}=175 \mathrm{MPa}-$ maximum value transverse to the weld, in heat-affected-zone (HAZ). There is no data about post-weld-heat-treatment (PWHT), so the maximum possible value of residual stress, according to experience, has been applied, [14].

- Curvature effect is negligible $(t / D=50 / 2075 \approx$ $0.025)$.

Having this in mind, the stress intensity factor is calculated as follows: $K_{\mathrm{I}}=\sigma \sqrt{ } \pi \mathrm{a}$; where $\sigma$ is remote stress $\left(\sigma=p R / 2 t+\sigma_{\mathrm{R}}\right)=259 \mathrm{MPa}$, a is crack half-length $(5 \mathrm{~mm})$ : $K_{\mathrm{I}}=\left(p R / 2 t+\sigma_{\mathrm{R}}\right) \sqrt{\pi \mathrm{a}}=1026 \mathrm{MPa} \sqrt{\mathrm{mm}}$, being $65 \%$ of $K_{\mathrm{Ic}}$.

Plastic collapse ratio has been calculated as follows: $S_{\mathrm{R}}$ $=\sigma_{\mathrm{n}} / \sigma_{\mathrm{F}} ; \sigma_{\mathrm{n}}=p \cdot R / 2 \cdot t=84 \mathrm{MPa}$, no reduction cross-section (negligible), $\sigma_{\mathrm{F}}=\left(R_{\mathrm{eH}}+R_{\mathrm{M}}\right) / 2=575 \mathrm{MPa} ; S_{\mathrm{R}}=0.15$. Thus, the coordinates are $(0.15,0.65)$, as shown in Fig. 4.

Now, one can calculate the probability of failure, as the ratio between the distance of the operating point from the zero point, and the appropriate distance between the point on the limiting curve and zero point. The probability is 0.64 for the point corresponding to design pressure (Very high risk, brown field in column VH, Tab. 1).

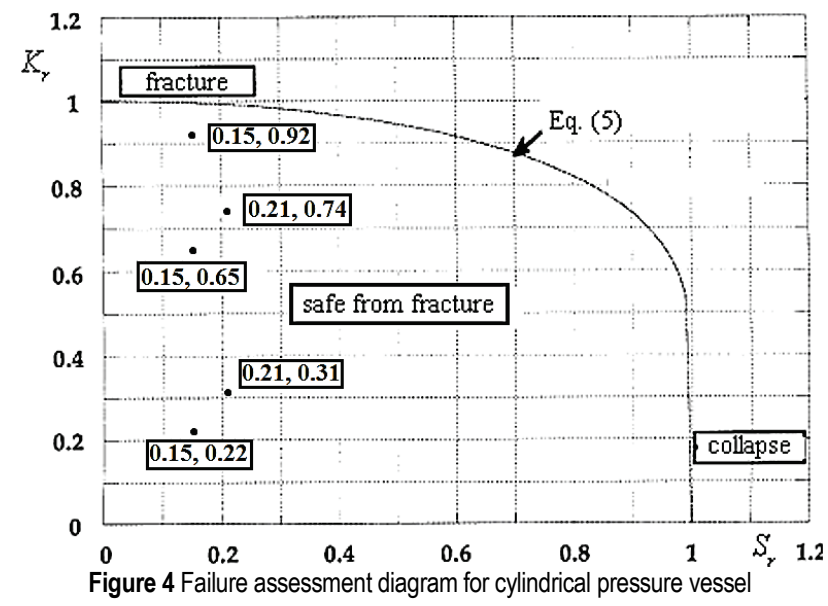

Three important effects now can be followed:

1) Common practice in conservative approach is to assume double size of a defect, just for the case that operator has not evaluated the size correctly, leading to the point $(0.15,0.92)$ and the probability 0.91 .

2) Water proof test pressure (43\% higher than the design pressure), raises probability from 0.64 to 0.75 .

3) If one neglects residual stresses, the point in FAD goes to much lower (deeper) part of the safe region, $(0.15,0.22)$, reducing probability to relatively low value $(0.24)$. Therefore, in this case, water proof is not a problem, because it raises probability up to 0.34 , point $(0.21,0.31)$.

Finally, for the probability of failure due to human factor effects, survey results are used, based on 18 questions (Q1-Q18), listed in Tab. 1. Every answer is quantified from 1 to 5 , some of them as "negative", and the remaining as "positive" (marked in red bold letters). The average value of replies is shown in row AV, second from the bottom, whereas the remaining value is shown in the bottom row, marked as RV. In the case of "negative" question, relevant quantity is given in the row RV, whereas in the case of "positive" question relevant value is given in the row AV. In both cases it was always the smaller value! Twenty replies $(\mathrm{O} 1-\mathrm{O} 20)$ are taken as relevant for this purpose, and presented in Tab. 2. The whole questionnaire has been statistically analysed and presented in details in [13]. Based on that analysis, 20 operators have provided relevant answers, which are used here for further analysis.

The average value for 20 operators and 18 questions (Q1-Q18) is then 23.5\%. Now, we can introduce the third axis, in addition to already common two axes, or we can combine two probabilities into one, getting "standard" diagram, as shown in Fig. 1.

In this case we will use standard risk matrix, because we have only one value for the probability due to human factor, not to mention also fixed value for the consequence. Therefore, although there are 3 coordinates, 3D presentation would be obsolete, because for one pressure vessel there is only one coordinate for consequence and one for probability due to human factor. Therefore, in the case presented in this paper, the consequence is kept as $\mathrm{VH}$, and probability to take into account the effect of human resources is re-calculated. Toward this aim, probabilities due to material defects, as well as probability due to human factor, have been subtracted from 1 , and multiplied, to get "inverse" values, which are then "inversed" back to the final probabilities, as follows:

- $\quad$ Point $(0.15,0.65): 1-(1-0.64) \cdot(1-0.235)=0.72$

- $\quad$ Point $(0.15,0.92): 1-(1-0.91) \cdot(1-0.235)=0.93$

- $\quad$ Point $(0.21,0.74): 1-(1-0.75) \cdot(1-0.235)=0.81$

- $\quad$ Point $(0.15,0.22): 1-(1-0.24) \cdot(1-0.235)=0.42$

- $\quad$ Point $(0.21,0.31): 1-(1-0.34) \cdot(1-0.235)=0.49$

Since all points are with VH consequence, one can see that, for the standard risk matrix presentation, points $(0.15,0.22)$; and $(0.21,0.31)$ are positioned in the high risk region, whereas the remaining three points are in the very high risk region, indicating detrimental effects of residual stresses, eventual misreading of NDT findings and/or water proof test. 
Table 2 Results for the human factor effects based on questionnaire

\begin{tabular}{|c|c|c|c|c|c|c|c|c|c|c|c|c|c|c|c|c|c|c|c|c|}
\hline & Q1 & Q2 & Q3 & Q4 & Q5 & Q6 & Q7 & Q8 & Q9 & Q10 & 11 & Q12 & Q13 & Q14 & Q15 & Q16 & Q17 & Q18 \\
\hline O1 & 3 & 2 & 2 & 3 & 4 & 4 & 3 & 1 & 5 & 2 & 4 & 3 & 3 & 5 & 4 & 4 & 4 & 4 \\
\hline 02 & 5 & 5 & 5 & 1 & 5 & 4 & 1 & 1 & 5 & 1 & 5 & 5 & 5 & 5 & 5 & 5 & 5 & 3 \\
\hline O3 & 2 & 2 & 5 & 2 & 3 & 3 & 2 & 2 & 4 & 2 & 4 & 3 & 3 & 5 & 4 & 4 & 4 & 4 \\
\hline O4 & 2 & 2 & 5 & 2 & 3 & 3 & 2 & 2 & 5 & 2 & 4 & 3 & 3 & 5 & 4 & 4 & 4 & 4 \\
\hline O5 & 2 & 2 & 5 & 2 & 3 & 3 & 2 & 2 & 4 & 2 & 4 & 3 & 3 & 5 & 4 & 4 & 4 & 4 \\
\hline O6 & 3 & 2 & 5 & 2 & 3 & 4 & 2 & 1 & 5 & 2 & 4 & 3 & 3 & 5 & 4 & 4 & 4 & 4 \\
\hline O7 & 2 & 2 & 5 & 3 & 4 & 3 & 2 & 1 & 4 & 2 & 4 & 3 & 3 & 5 & 4 & 4 & 4 & 4 \\
\hline O8 & 1 & 1 & 5 & 1 & 4 & 5 & 1 & 1 & 5 & 1 & 5 & 5 & 5 & 5 & 5 & 5 & 5 & 5 \\
\hline O9 & 2 & 2 & 5 & 1 & 5 & 5 & 1 & 1 & 5 & 1 & 5 & 5 & 5 & 5 & 5 & 5 & 5 & 5 \\
\hline O10 & 2 & 2 & 5 & 1 & 5 & 5 & 1 & 1 & 5 & 1 & 5 & 5 & 5 & 5 & 5 & 5 & 5 & 5 \\
\hline O11 & 3 & 1 & 5 & 4 & 4 & 5 & 2 & 2 & 4 & 2 & 4 & 5 & 4 & 5 & 3 & 4 & 5 & 4 \\
\hline O12 & 3 & 1 & 5 & 2 & 3 & 2 & 3 & 2 & 4 & 2 & 5 & 5 & 4 & 5 & 4 & 4 & 4 & 4 \\
\hline O13 & 3 & 1 & 5 & 2 & 2 & 4 & 2 & 2 & 4 & 2 & 5 & 5 & 4 & 5 & 4 & 4 & 4 & 5 \\
\hline O14 & 1 & 1 & 5 & 1 & 1 & 5 & 2 & 4 & 5 & 1 & 5 & 5 & 5 & 3 & 5 & 5 & 5 & 5 \\
\hline O15 & 2 & 2 & 5 & 1 & 3 & 5 & 1 & 1 & 5 & 1 & 5 & 5 & 5 & 5 & 5 & 5 & 5 & 5 \\
\hline O16 & 2 & 5 & 4 & 5 & 4 & 3 & 2 & 2 & 4 & 3 & 5 & 4 & 5 & 4 & 4 & 3 & 4 & 5 \\
\hline O17 & 5 & 5 & 5 & 5 & 5 & 4 & 4 & 3 & 4 & 2 & 5 & 5 & 5 & 3 & 5 & 5 & 3 & 5 \\
\hline O18 & 5 & 5 & 5 & 3 & 2 & 4 & 3 & 2 & 2 & 4 & 5 & 4 & 5 & 3 & 4 & 3 & 4 & 5 \\
\hline O19 & 1 & 1 & 2 & 1 & 4 & 5 & 1 & 2 & 5 & 1 & 5 & 5 & 5 & 5 & 5 & 5 & 5 & 5 \\
\hline O20 & 5 & 5 & 5 & 3 & 2 & 4 & 3 & 2 & 2 & 4 & 5 & 4 & 5 & 3 & 4 & 3 & 4 & 5 \\
\hline AV & 0.54 & 0.49 & 0.93 & 0.45 & 0.66 & 0.80 & 0.40 & 0.35 & 0.86 & 0.38 & 0.93 & 0.85 & 0.85 & 0.91 & 0.87 & 0.85 & 0.87 & 0.90 \\
\hline RV & 0.46 & 0.51 & 0.07 & 0.55 & 0.34 & 0.20 & 0.60 & 0.65 & 0.14 & 0.62 & 0.07 & 0.15 & 0.15 & 0.09 & 0.13 & 0.15 & 0.13 & 0.10 \\
\hline
\end{tabular}

\section{CONCLUSIONS}

Based on the results shown here, one can conclude the following:

- Risk matrix is simple, but useful engineering tool for assessment of pressure vessel integrity, based on definition of risk, i.e. consequence $\mathrm{x}$ probability.

- Approach used here avoids unnecessary complicated procedures for consequence and probability calculation, i.e. risk evaluation.

- The effects of water proof test pressure, residual stresses and/or NDT readings, can be easily taken into account and quantified, completing the data needed by managers to make important decisions on further use of pressure equipment.

\section{REFERENCES}

[1] Jovičić, R., Sedmak, A., Sedmak, S., Milović, Lj., \& Jovičić, K. (2012). Leakage of an austenitic steel $\mathrm{CO}_{2}$ storage tank. Structural Integrity and Life, 12, 105-108.

[2] Bakić, R., Milović, Lj., Jovičić, R., \& Sedmak, S. (2013). Quality assurance of storage tanks after in-service crack repairs. Structural Integrity and Life, 13, 63-74.

[3] Kirin,S., Božić, M., Brzaković, M., \& Vucetic, I. (2015). Challenges of Future Research in the Area of Industrial Safety. Structural Integrity and Life, 15, 71-78.

[4] Kirin, S., Stanojević, P., Miljanović, I., Sedmak, A., Perić, T., \& Ilić, P. (2015). Influence of the Human Factor on Risks in an Open-Pit Mine. Structural Integrity and Life, 15, 117-128.

[5] Stanojević, P., Jovanović, A., Kirin, A., Misita, M., Orlić, B., \& Eremić, S. (2015). Some Achievements in RBIM Implementation According to RIMAP Approach. Structural Integrity and Life, 15, 79-84.

[6] Sedmak, A., Kirin, S., Golubovic, T., Mitrovic, S., \& Stanojevic, P. (2016). Risk based approach to integrity assessment of a large spherical presseure vessel. ECF21, Catania, Structural Integrity Procedia, 3654-3659. https://doi.org/10.1016/j.prostr.2016.06.454

[7] Kirin, S., Martic, I., Sedmak, A., Alkateb, M., \& Stanojevic, P. (2017). Structural integrity assessment of a cylindrical pressure vessel by using the risk based approach. Int. Conf. Struct. Int. and Durability (ISCID 2017) / Dubrovnik, 241242

[8] Algool, M., Sedmak, A., Kirin, S., Rakičević, B., \& Bakić, R. (2016). Industrial safety of pressure vessels - structural integrity and risk assessment point of view. Hemijska Industrija, 70, 685-694. https://doi.org/10.2298/HEMIND150423005S

[9] Standard API 510. (2014). Pressure Vessel Inspection Code: In-Service Inspection, Rating, Repair, and Alteration. American Petroleum Institute.

[10] API 581. (2010). The standard for quantitative Risk Based Inspection. American Petroleum Institute.

[11] Jovanovic, A., Kauer, R., \& Renner, M. (2011). The "story" of RIMAP: from a research project over CWA to EN and global market... and iNTeg-Risk (FP7)! Seminar Standardisation in Research and Innovation, Brussels.

[12] Anderson, T. (2003). Fracture Mechanics - Fundamental and Applications. CRC Press.

[13] Golubović, T. (2018). Integration of human and organizational factors into risk and structural integrity assessment model for pressure equipment, unpublished D.Sc. thesis in Serbian. University of Belgrade.

[14] Sedmak, A., Sedmak, S., \& Milovic, Lj. (2011). Pressure equipment integrity assessment by elastic-plastic fracture mechanics methods, Monograph, DIVK, Belgrade.

[15] Vucetic, I., Kirin, S., Vucetic, T., Golubovic, T., \& Sedmak, A. (2018). Risk Analysis in the Case of Air Storage Tank Failure. Structural Integrity and Life, 18, 3-6. 


\section{Contact information:}

Tamara GOLUBOVIĆ, Assistant

University of Belgrade, Faculty of Mechanical Engineering,

Kraljice Marije 16, 11120 Belgrade, Serbia

E-mail: tsedmak@mas.bg.ac.rs

\section{Aleksandar SEDMAK, Prof. PhD}

University of Belgrade, Faculty of Mechanical Engineering,

Kraljice Marije 16, 11120Belgrade, Serbia

E-mail: asedmak@mas.bg.ac.rs

Vesna SPASOJEVIĆ-BRKIĆ, Prof. PhD

University of Belgrade, Faculty of Mechanical Engineering,

Kraljice Marije 16, 11120 Belgrade, Serbia

E-mail: vspasojević@mas.bg.ac.rs

Snežana KIRIN, PhD

Innovation Centre of Faculty of Mechanical Engineering, Belgrade

Kraljice Marije 16, 11120 Belgrade, Serbia

E-mail: snezanakirin@yahoo.com

Ivan RAKONJAC, $\mathrm{PhD}$

EDUKONS University, Novi Sad,

Faculty of Project and Innovation Management,

Bože Jankovića 14, Voždovac, 11000 Belgrade, Serbia

E-mail: ivan.rakonjac@gmail.com 